\section{Dinheiro, profissão e partido: a vitória na eleição para deputado federal no Brasil em 2010}

Recebido: 24.04.13

Aprovado: 21.10 .13

\author{
Emerson Urizzi Cervi, \\ Luiz Domingos Costa, \\ Adriano Codato \& \\ Renato Perissinotto*
}

Resumo: A partir de banco de dados com 4.124 candidatos à Câmara dos Deputados nas eleições de 2010, este artigo avalia o peso das variáveis "ocupação", "tipo de partido político" e "financiamento das campanhas" no desempenho eleitoral dos competidores a uma cadeira no legislativo federal. $\mathrm{O}$ artigo conclui que pertencer a partidos políticos grandes e organizados, ter experiência política prévia (especialmente na própria Câmara dos Deputados) e possuir alta capacidade de arrecadação de recursos financeiros são condições fundamentais para determinar o sucesso eleitoral do candidato. Tais dados apontam para a profissionalização dos quadros eleitos no Brasil e para a crescente institucionalização do universo político nacional.

Palavras-chave: eleições de 2010, deputado federal, financiamento de campanha, recrutamento político, político profissional.

\section{Introdução}

E studos recentes que analisaram as chances de candidatos e eleitos para posições legislativas no Brasil até 2006 têm sido muito esclarecedores a respeito das variáveis que condicionam o sucesso eleitoral, especialmente nas disputas para a Câmara dos Deputados. De acordo com alguns desses trabalhos, sabemos, por exemplo, que as diferenças entre candidatos e eleitos se deve, em parte, às ocupações mais intimamente relacionadas às atividades políticas (Braga, Veiga \& Miríade, 2009); outros estudos afirmam que, entre aqueles que se candidatam à Câmara dos Deputados, terão maiores chances de sucesso eleitoral aqueles que já estiveram naquela casa anteriormente (Perissinotto \& Miríade, 2009; Perissinotto \& Bolognesi, 2010); há ainda pesquisas que revelam que os candidatos munidos de mais recursos financeiros são também os com maiores probabilidades de vencer a disputa eleitoral para o cargo de deputado federal (Lemos, Marcelino \& Pederiva, 2010).

Este artigo dialoga com esses estudos a partir de um novo conjunto de evidências e sugere conclusões mais robustas por analisar conjuntamente variáveis que, em outros trabalhos, são trabalhadas de maneira isolada, a saber: a posição social (medida pela ocupação), o pertencimento partidário e a arrecadação financeira

\footnotetext{
* Emerson Urizzi Cervi, Universidade Federal do Paraná (UFPR).<ecervi7@ gmail.com>.

Luiz Domingos Costa, Centro Universitário Uninter (Uninter) / Núcleo de Pesquisa em Sociologia Política Brasileira (Nusp-UFPR). <ldomingosc@uol. com.br>

Adriano Codato, Universidade Federal do Paraná (UFPR) / Núcleo de Pesquisa em Sociologia Política Brasileira (NuspUFPR).<acodato@ terra.com.br>. Renato Perissinotto, Universidade Federal do Paraná (UFPR) / Núcleo de Pesquisa em Sociologia Política Brasileira (NuspUFPR).<monseff@ gmail.com>.
} 
1. Utilizamos a definição de "político profissional" do Tribunal Superior Eleitoral do Brasil. Políticos profissionais são aqueles que se autodeclararam (na ficha de inscrição como candidato) vereador, prefeito, deputado estadual, deputado federal, senador e governador. Se ele não se declarou como pertencendo a uma dessas categorias - ainda que em outros trabalhos e conforme outras agregações ele pudesse ser considerado como um político de carreira - não entrou nesse grupo e não fo assim considerado em nosso estudo. de campanha. A questão mais geral que orienta este estudo é a seguinte: tendo em vista a consolidação das regras da competição política democrática no Brasil, é possível verificar a existência de um campo político mais autônomo - no sentido proposto por Bourdieu (1998) - e, por conseguinte, de uma classe política mais profissionalizada? Esse hermetismo que caracteriza o universo político implica em considerar tanto os processos históricos de produção dos profissionais da política, numa perspectiva mais geral, quanto os procedimentos efetivos, isto é, o "jogo político" jogado pelos políticos reais, com suas regras, posturas, valores e, principalmente, estratégias.

Duas mudanças importantes de enfoque sobre o problema do "recrutamento político" são fundamentais para situar esse empreendimento. Uma primeira, de tipo teórico, que insiste não somente nas características institucionais condicionantes do sistema político, mas também nos predicados de social background do pessoal político, procurando mensurar como variáveis sociais de médio e longo prazo habilitam candidatos e pavimentam o caminho que leva um indivíduo a disputar e ganhar uma vaga no universo político (Giddens, 1974; Putnam, 1976; Stanworth \& Giddens, 1974). Sob esse ângulo, o tipo de elite política resulta de espaços sociais determinados pela configuração de uma dada sociedade, de modo que a ambição política é resultado não de uma "vocação" abstrata, mas da combinação complexa de fatores socioeconômicos que caracterizam uma sociedade (Gaxie, 1980). A segunda mudança de enfoque no entendimento do significado e na análise do recrutamento político é metodológica. Trata-se de seguir a proposição de Pippa Norris (1997), que sustenta que o entendimento correto do processo de recrutamento político requer o estudo do conjunto daqueles que efetivamente se lançam no empreendimento eleitoral, incluindo sejam aqueles que não logram êxito (os candidatos perdedores), sejam os aspirantes a candidatos (etapa exclusivamente voltada para o momento da seleção partidária, não contemplada na discussão que apresentaremos a seguir).

O artigo sustenta, a partir dos dados coletados, três proposições:

a. ser político profissional ${ }^{1} \mathrm{e}$, especialmente, ser candidato à reeleição na Câmara dos Deputados aumenta enormemente as chances de triunfo do competidor;

b. a condição de político profissional tende a ser ainda mais potencializada se o aspirante pertencer a um dos quatro grandes partidos políticos nacionais; e

c. quanto mais importantes os recursos financeiros para a campanha eleitoral, maiores as chances de vitória. 
Todavia, o ponto fundamental aqui é mostrar quais são as consequências desses três fatos que não são apenas simultâneos, mas se reforçam mutuamente.

Assim, a partir deste estudo de caso, pode-se começar a pensar, com os novos dados aqui apresentados, três processos mais gerais para compreender e explicar o funcionamento da democracia brasileira contemporânea: a institucionalização progressiva da competição política entre nós (e, consequentemente, a institucionalização dos partidos políticos e dos aparelhos legislativos); a autonomização do universo político em relação aos demais universos sociais (o que implica em assumir, em alguma medida, que o campo político "possui em si mesmo o princípio e a regra do seu funcionamento" (Bourdieu, 2000: 52)); e a profissionalização dos agentes e de suas estratégias/carreiras políticas. Cada vez menos as fronteiras do campo político nacional são fluidas, franqueadas a franco-atiradores e há cada vez menos oportunidades para o sucesso de outsiders (Marenco dos Santos, 2000). Ainda que não se verifique um padrão de carreira direcionado prioritariamente ao Legislativo, políticos do Legislativo tendem, quando decidem permanecer nele, a ter mais sucesso que os seus desafiantes. Consideramos que os três processos não estão equidistantes entre si. Enquanto a institucionalização encontra-se na dimensão coletiva, os processos de autonomização e profissionalização aproximam-se mais um do outro.

O artigo está estruturado em três seções e uma conclusão. Na primeira seção, analisamos o impacto das diversas ocupações profissionais nas oportunidades eleitorais dos candidatos, comparando o grupo dos eleitos e dos não eleitos. Na segunda seção, procuramos mostrar como o pertencimento a determinados partidos políticos aumenta significativamente as chances de um candidato vir a ser vitorioso. $\mathrm{Na}$ terceira parte, o artigo se volta para a análise do impacto dos recursos financeiros sobre as chances de sucesso na disputa. Por fim, na conclusão, fazemos algumas considerações sobre como tais dados podem ser interpretados como evidências de um processo mais vasto de profissionalização das carreiras e de institucionalização do campo político no Brasil.

As discussões feitas neste artigo têm como base dois bancos de dados do TSE: o primeiro, formado pelos candidatos que obtiveram votação para a Câmara de Deputados; o segundo, composto por aqueles que prestaram contas das receitas e despesas de campanha. Por essa razão, o artigo só leva em consideração os casos que constam dos dois bancos, o que compreende 4.124 candidaturas válidas, isto é, definidas como aptas pelos Tribunais Regionais Eleitorais dos estados. Dessas, 543 foram classificadas como de "político", que são aqueles indivíduos que se apresentaram como detentores de cargos eletivos prévios. Entre os políticos encontram-se um prefeito, seis senadores, 163 vereadores e 373 deputados. 
2. Os resíduos padronizados indicam a força da relação entre categorias das variáveis analisadas. Se positivos e acima de 1,96 , indicam associação positiva entre as categorias. Se negativos e também acima de 1,96 eles indicam o contrário.

\section{Políticos de profissão e os outros na corrida eleitoral em 2010}

Para iniciar a análise das diversas ocupações no grupo dos eleitos e dos não eleitos na disputa para a Câmara dos Deputados em 2010, apresentamos a Tabela 1 com informações sobre percentuais e também os resíduos padronizados das respectivas distribuições ${ }^{2}$.

TABELA 1

OCUPAÇÃO POR RESULTADO ELEITORAL NA DISPUTA PARA A CÂMARA DOS DEPUTADOS (2010)

\begin{tabular}{|l|c|c|c|c|c|c|}
\hline \multirow{2}{*}{\multicolumn{1}{|c|}{ ocupação }} & \multicolumn{3}{|c|}{ não eleito } & \multicolumn{3}{c|}{ eleito } \\
\cline { 2 - 7 } & $N$ & $\%$ & Res. Pad. & N & $\%$ & Res.Pad. \\
\hline trabalhador & 370 & $96,6 \%$ & 1,9 & 13 & $3,4 \%$ & $-5,0$ \\
\hline magistério & 212 & $93,4 \%$ & 0,9 & 15 & $6,6 \%$ & $-2,5$ \\
\hline pequeno comerciante & 215 & $96,8 \%$ & 1,5 & 7 & $3,2 \%$ & $-3,9$ \\
\hline eclesiástico & 26 & $92,9 \%$ & 0,3 & 2 & $7,1 \%$ & $-0,8$ \\
\hline funcionário público & 492 & $97,6 \%$ & 2,4 & 12 & $2,4 \%$ & $-6,4$ \\
\hline profissional liberal & 968 & $89,8 \%$ & 0,8 & 110 & $10,2 \%$ & $-2,1$ \\
\hline político & 260 & $47,9 \%$ & $-9,9$ & 283 & $52,1 \%$ & 26,2 \\
\hline empresário & 415 & $91,4 \%$ & 0,9 & 39 & $8,6 \%$ & $-2,3$ \\
\hline aposentado & 160 & $98,8 \%$ & 1,5 & 2 & $1,2 \%$ & $-4,0$ \\
\hline outras & 493 & $94,3 \%$ & 1,6 & 30 & $5,7 \%$ & $-4,3$ \\
\hline Fonte: Núcleo de Pesquisa em Sociologia Política Brasileira (Nusp/UFPR). & & & \\
\hline
\end{tabular}

Políticos profissionais foram os mais bem-sucedidos eleitoralmente: $52 \%$ se elegeram, contra $10 \%$ de profissionais liberais, $8,6 \%$ entre aqueles que se declararam empresários e 6,6\% entre os professores. Esse achado é corroborado pelos resíduos padronizados. A Tabela 1 mostra que os resíduos padronizados das categorias profissionais para os não eleitos ficam abaixo do limite crítico de 1,96 para quase todos os casos, exceto em duas classes. Para os funcionários públicos não eleitos, o resíduo de + 2,4 indica que temos mais funcionários públicos não eleitos do que esperaríamos encontrar se a distribuição fosse normal. Vale a pena destacar o baixo desempenho dos funcionários públicos, já que se trata de grupo historicamente bem representado na elite política brasileira (cf. Rodrigues, 2002; 2006). Em função da especialização do campo político e das novas condições de competitividade, eles tendem cada vez mais a perder espaço. A votação média dos burocratas ficou muito próxima dos trabalhadores e dos pequenos comerciantes, superando apenas a votação média dos aposentados. O outro caso é o dos políticos profissionais, com resíduo padronizado de - 9,9 para o grupo dos não eleitos. Isso demonstra que, considerando a distribuição de todos os candidatos que já eram políticos profissionais antes de entrar na disputa, 
encontramos menos deles entre os não eleitos do que esperávamos encontrar, caso eles se distribuíssem igualmente entre as duas categorias.

Já na coluna dos candidatos eleitos, os resíduos apresentam resultados distintos, ficando acima do limite crítico para a maioria das profissões. Outra característica importante é que para quase todas as demais categorias os resíduos foram significativos e negativos. Apenas para político profissional é que o resíduo padronizado dos eleitos é positivo e extremamente alto, ficando em 26,2. Isso demonstra que os políticos profissionais não apenas estão em menor número do que o esperado entre os não eleitos, mas, principalmente, que eles estão em maior proporção do que a esperada entre os eleitos para Câmara de Deputados em 2010, valendo o oposto para as demais ocupações ${ }^{3}$.

Os dados da Tabela 1, porém, têm um limite importante. A informação, assim agregada, não separa os políticos profissionais entre seus vários subgrupos: vereadores, prefeitos, deputados e senadores. Como veremos, faz toda a diferença já ser deputado, tanto federal quanto estadual. Assim, para identificar se o efeito positivo nos resíduos padronizados se distribui igualmente entre todos os tipos de políticos ou se, ao contrário, concentra-se naqueles que já eram deputados, apresentamos os dados da Tabela 2.

TABELA 2

OCUPAÇÃO, EXCLUINDO DEPUTADOS, POR RESULTADO ELEITORAL NA DISPUTA PARA A CÂMARA DOS DEPUTADOS (2010)

\begin{tabular}{|l|c|c|c|c|c|c|}
\hline \multirow{2}{*}{ ocupação } & \multicolumn{3}{|c|}{ não eleito } & \multicolumn{3}{c|}{ eleito } \\
\cline { 2 - 7 } & $N$ & $\%$ & Res.Pad. & $N$ & $\%$ & Res.Pad. \\
\hline trabalhador & 370 & $96,6 \%$ & 0,6 & 13 & $3,4 \%$ & $-2,4$ \\
\hline magistério & 212 & $93,4 \%$ & 0,0 & 15 & $6,6 \%$ & 0,0 \\
\hline pequeno comerciante & 215 & $96,8 \%$ & 0,5 & 7 & $3,2 \%$ & $-2,0$ \\
\hline eclesiástico & 26 & $92,9 \%$ & 0,0 & 2 & $7,1 \%$ & 0,1 \\
\hline funcionário público & 492 & $97,6 \%$ & 1,0 & 12 & $2,4 \%$ & $-3,6$ \\
\hline profissional liberal & 968 & $89,8 \%$ & $-1,2$ & 110 & $10,2 \%$ & 4,7 \\
\hline político (exceto deputado) & 155 & $91,2 \%$ & $-0,3$ & 15 & $8,8 \%$ & 1,2 \\
\hline empresário & 415 & $91,4 \%$ & $-0,5$ & 39 & $8,6 \%$ & 1,7 \\
\hline aposentado & 160 & $98,8 \%$ & 0,7 & 2 & $1,2 \%$ & $-2,6$ \\
\hline outras & 493 & $94,3 \%$ & 0,2 & 30 & $5,7 \%$ & $-0,7$ \\
\hline Fonte: Núcleo de Pesquisa em Sociologia Política Brasileira (Nusp/UFPR). & & & \\
\hline
\end{tabular}

Como indicamos anteriormente, o conjunto de políticos profissionais soma 543 candidatos a deputado federal em 2010, sendo que destes, 283 conseguiram eleger-se e 260 foram derrotados. No entanto, quando excluímos os deputados dessa catego-

3. Isso se confirma quando se analisa a votação nominal média por ocupação agregada. Enquanto os políticos somaram 74.983 votos em média, os demais grupos ocupacionais apresentam médias muito mais baixas: profissionais liberais atingiram 20.969 votos, eclesiásticos, 19.442, empresários, 17.657, professores contabilizaram em média $15.491 \mathrm{e}$ todas as demais ocupações ficaram abaixo disso. 
ria, o número de candidatos à Câmara de Deputados cai para 170, sendo que 155 são derrotados e apenas 15 conseguem uma cadeira.

Os resíduos padronizados dos não eleitos continuam abaixo do limite crítico de significância para todas as categorias profissionais. Nem mesmo funcionário público e político profissional, quando são retirados os deputados, ficaram acima de 1,96. Já entre os eleitos, a exclusão dos deputados tem efeitos em várias categorias profissionais. A primeira diferença significativa é na própria categoria político profissional que, agora, apresenta resíduos padronizados abaixo de 1,2, indicando não existir relação entre ser eleito e ser político profissional quando eliminados os deputados-candidatos. As demais categorias que apresentam resíduos significativos e negativos mantiveram a mesma tendência, indicando que a não participação dos deputados na disputa teria baixo efeito sobre o desempenho delas. Exceto para a categoria dos profissionais liberais, que passou de um resíduo de- 2,1 para os eleitos, quando os deputados são incluídos na disputa (ver Tabela 1), para $+4,7$ quando subtraímos os candidatos-deputados da categoria político profissional (Tabela 2). Os dados indicam, portanto, que, com os deputados na disputa, as chances de eleger candidatos políticos profissionais aumentam; sem eles, quem ganha mais espaço para a Câmara de Deputados é a categoria dos profissionais liberais. Todas as demais ou ficam abaixo no limite crítico de significância ou são significativas com sinal negativo.

Evidentemente, tais resultados são a resposta a um exercício meramente contrafactual ("o que aconteceria se os candidatos-deputados não concorressem?"). Porém,

TABELA 3

OCUPAÇÃO "POLÍTICO" DESAGREGAdA POR RESULTADO ELEITORAL NA DISPUTA PARA A CÂMARA DOS DEPUTADOS (2010)

\begin{tabular}{|c|c|c|c|}
\hline políticos & não eleito & eleito & total \\
\hline \multirow{2}{*}{ prefeito } & 1 & 0 & 1 \\
\hline & $100,0 \%$ & $0,0 \%$ & $100,0 \%$ \\
\hline \multirow{2}{*}{ senador } & 3 & 3 & 6 \\
\hline & $50,0 \%$ & $50,0 \%$ & $100,0 \%$ \\
\hline \multirow{2}{*}{ deputado } & 105 & 268 & 373 \\
\hline & $28,2 \%$ & $71,8 \%$ & $100,0 \%$ \\
\hline \multirow{2}{*}{ vereador } & 151 & 12 & 163 \\
\hline & $92,6 \%$ & $7,4 \%$ & $100,0 \%$ \\
\hline \multirow{2}{*}{ total } & 260 & 283 & 543 \\
\hline & $47,9 \%$ & $52,1 \%$ & $100 \%$ \\
\hline
\end{tabular}
conseguimos mostrar que os deputados são os maiores responsáveis pelo desempenho positivo dos candidatos políticos profissionais. Em outras palavras, quem eleva as chances de eleição da categoria político profissional são os candidatos à reeleição: deputados federais. Eles representam $68,5 \%$ do total de candidatos que se autodeclararam políticos e, mais importante, representam a quase totalidade dos políticos profissionais eleitos: 94,7\%. A Tabela 3 exibe de forma mais detalhada esses dados.

Quando a categoria "político" é desagregada, percebemos que a sobrerrepresentação dos políticos eleitos em relação aos candidatos é especialmente válida para 
o caso dos deputados (72\%), seguida de senadores candidatos e vitoriosos (50\%). Com relação aos vereadores, o percentual de sucesso é bastante baixo (7,5\%). Este último dado é particularmente importante, pois indica que não é fácil partir de uma posição reconhecidamente inferior na hierarquia da carreira e saltar para posições mais altas sem antes passar algum tempo nas escalas intermediárias ou mesmo na posição a que se almeja chegar (no caso, a de deputado federal). Isso indica também que a carreira política no Brasil está cada vez mais estruturada e hierarquizada, sendo difícil progredir por saltos.

\section{O político de carreira e os partidos nacionais}

As discussões em torno de como diferentes partidos recrutam as suas bancadas em diferentes estratos sócio-ocupacionais conta com importantes achados: um correlaciona diferentes perfis ideológicos dos partidos nacionais (em termos de centro / esquerda / direita) com diferentes perfis profissionais de seus quadros (Rodrigues, 2002); outro sustenta que carreiras de políticos de esquerda não são iguais a carreiras dos políticos de direita (Marenco dos Santos \& Serna, 2007).

Note-se, entretanto, que esses trabalhos priorizam os principais partidos do país (geralmente aqueles que possuem as quatro, cinco ou seis maiores bancadas na Câmara dos Deputados), deixando de lado organizações menores, mesmo aquelas que, se não chegam a receber o rótulo de partidos relevantes (isto é, com bancadas com mais de $5 \%$ da representação total da casa), estão longe de serem desprezíveis em termos ideológicos ou políticos. Como aqui estamos interessados na combinação da variável ocupacional "político profissional" com outras, veremos que é importante incluir nessa conta alguns dos partidos que não figuram entre as quatro grandes agremiações brasileiras, justamente porque a diferença entre as grandes, médias e pequenas agremiações partidárias representa um importante elemento para dimensionar a magnitude da presença de profissionais da política na Câmara Federal. Assim, do nosso ponto de vista, a comparação entre partidos é importante para saber se os políticos profissionais se distribuem igualmente pelas diversas legendas, ou se estão concentrados preferencialmente nos grandes partidos ${ }^{4}$.

Nossos dados demonstram que políticos profissionais encontram-se preferencialmente nos grandes partidos, aqueles que a literatura reputa como partidos relevantes (Marenco \& Serna, 2007; Braga, Veiga \& Miríade, 2009) isto é, os quatro que têm conquistado seguidamente as maiores bancadas federais: PT, PMDB, PSDB e DEM. Mas há outras organizações, não tão relevantes - como o PR e o PP -, que ocupam papel de destaque, com mais de $20 \%$ de seus candidatos sendo "políticos profissionais". O PR, por exemplo, lançou na disputa quase o mesmo número de políticos de carreira $(22,5 \%)$ que o PT (23\%).
4.Nosso objetivo portanto, não é analisar a complexa engrenagem interna de cada tipo de organização partidária. Sabe-se que diferentes tipos de partido atraem, selecionam e promovem os seus militantes a cargos políticos de destaque de maneira muito diferente entre si. Para esse ponto, ver Gallagher \& Marsh, 1988; Rahat \& Hazan 2001). Para uma discussão sobre o Brasil, ver Bolognesi (2013). 
TABELA 4

SUCESSO ELEITORAL NA DISPUTA

PARA A CÂMARA DOS DEPUTAdOS (2010)

\begin{tabular}{|c|c|c|c|c|}
\hline $\begin{array}{c}\text { partido } \\
\text { político }\end{array}$ & $\begin{array}{c}\text { sucesso } \\
\text { geral }\end{array}$ & $\begin{array}{c}\text { sucesso } \\
\text { não } \\
\text { políticos }\end{array}$ & $\begin{array}{c}\text { sucesso } \\
\text { políticos } \\
\text { (exceto } \\
\text { deputados) }\end{array}$ & $\begin{array}{c}\text { sucesso } \\
\text { deputados } \\
\text { federais }\end{array}$ \\
\hline PT & 0,28 & 0,08 & 0,16 & 0,81 \\
\hline PR & 0,27 & 0,09 & 0,03 & 0,72 \\
\hline DEM & 0,26 & 0,09 & 0,09 & 0,65 \\
\hline PMDB & 0,25 & 0,07 & 0,08 & 0,71 \\
\hline PP & 0,24 & 0,04 & 0,18 & 0,79 \\
\hline PSDB & 0,23 & 0,05 & 0,19 & 0,59 \\
\hline PSB & 0,14 & 0,06 & 0,00 & 0,83 \\
\hline PCdoB & 0,14 & 0,05 & 0,07 & 0,90 \\
\hline PRB & 0,07 & 0,03 & 0,15 & 0,60 \\
\hline PV & 0,04 & 0,02 & 0,12 & 0,56 \\
\hline PMN & 0,02 & 0,01 & 0,17 & 0,50 \\
\hline PSC & 0,1 & 0,03 & 0,18 & 0,67 \\
\hline PPS & 0,1 & 0,02 & 0,17 & 0,67 \\
\hline Montros & 0,04 & 0,02 & 0,09 & 0,68 \\
\hline Núcleo de Pesquisa em Sociologia Política Brasileira (Nusp/UFPR) & 0,69 \\
\hline & 0,15 & 0,05 & 0,12 & 0,17 \\
\hline
\end{tabular}

nificativas entre os partidos

políticos. PT, PR, DEM, PMDB, PP e PSDB são os partidos com as taxas mais altas de sucesso. Alguns partidos como PSB e PCdoB ocupam posições intermediárias e os demais partidos têm taxas muito baixas de vitória dos seus candidatos para a Câmara dos Deputados. As informações sobre o desempenho dos candidatos que já são políticos são mais ou menos equivalentes com os dados da coluna 1. Exceto pelos casos do PMDB, DEM, PSB e PR, todos os demais partidos exibem taxas de sucesso entre os políticos muito maiores do que as taxas de sucesso dos candidatos com outras ocupações. No entanto, é preciso observar que em alguns desses partidos isso se deve ao fato de que a maioria de seus candidatos políticos são deputados (dados desagregados na última coluna). Assim, o PSB parece não ter eleito nenhum candidato político, mas isso ocorre porque todos os candidatos políticos eleitos pelo PSB já são deputados.

Mais interessante, porém, é a profunda similaridade entre os partidos revelada pela quarta coluna da tabela, que concentra apenas os dados dos deputados-candidatos. Os números mostram que, em todos os partidos, a taxa de sucesso dos deputados-candidatos é bem maior do que a taxa de sucesso dos demais candidatos. 
Assim, a despeito das diferenças quanto à presença de políticos profissionais (mais frequentes nos grandes do que nos pequenos partidos), essa tabela demonstra que, mesmo nos partidos menores, as chances de se eleger estão profundamente vinculadas à profissionalização política. Mais ainda: a oportunidade de ser bem sucedido na Câmara dos Deputados está ligada ao exercício prévio do cargo de deputado federal.

Mesmo assim, a despeito da semeIhança revelada, os dados da Tabela 4 continuam mostrando que partidos com maior número de candidatos-deputados tendem a ter maiores taxas de sucesso eleitoral. Isso fica ainda mais claro com a apresentação do Gráfico 1.

O Gráfico 1 apresenta a relação entre número de candidatos à reeleição e o número de triunfos por partido. O coeficiente de correlação
GRÁFICO 1

DESEMPENHO DOS CANDIDATOS À REELEIÇÃO

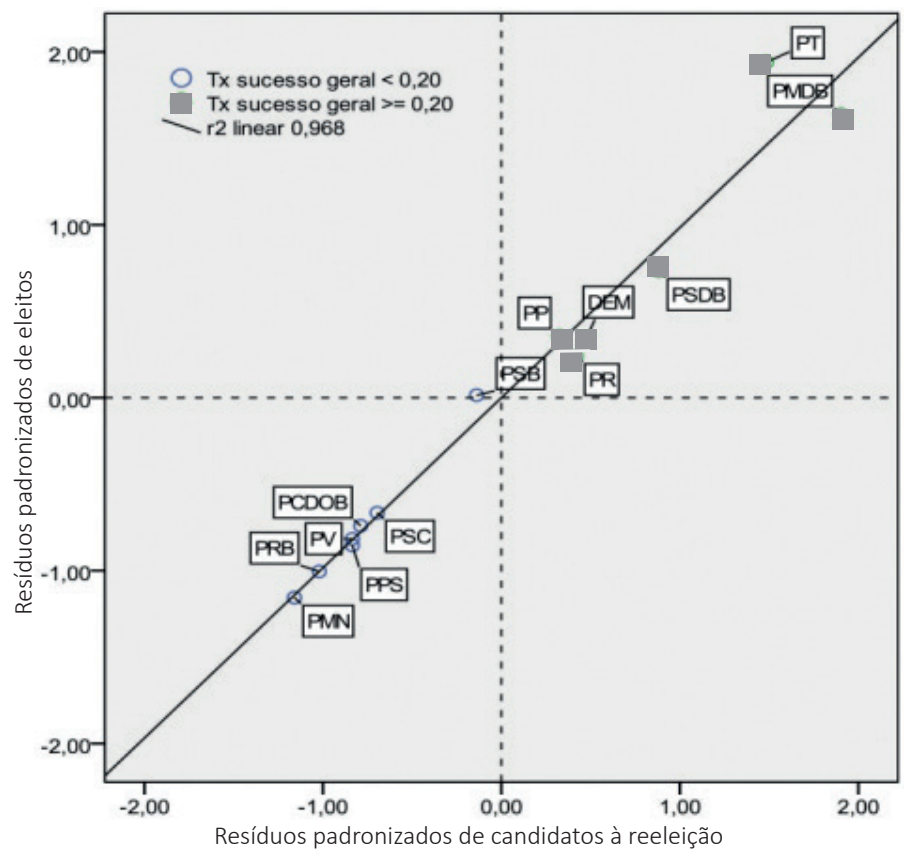

Fonte: Núcleo de Pesquisa em Sociologia Política Brasileira (Nusp/UFPR).

é extremamente alto, com 96,8\% de correlação entre candidatos que já são deputados federais e eleitos. A reta de regressão fica muito próxima de 45 graus, indicando forte relação entre os resíduos das duas variáveis. Todos os partidos estão muito próximos da reta, indicando baixos índices de erro. Mais ilustrativo ainda é perceber que os partidos com taxa de sucesso acima de 0,20 concentram-se no quadrante superior das duas variáveis (têm resíduos positivos para eleitos e candidatos-políticos), isto é, PMDB, PT, DEM, PSDB, PP, PSD e PR. Já os partidos que tiveram taxa de sucesso abaixo de 0,20 ficaram no quadrante negativo para as duas variáveis (resíduos negativos para número de eleitos e para número de candidatos-políticos), isto é, PCdoB, PV, PSC, PPS, PMN e PRB. Nenhum partido ficou nos quadrantes inconsistentes, ou seja, com muitos candidatos políticos e poucos eleitos ou vice-versa. $O$ PSB fica no limite. Todos esses resultados mostram que a variável político profissio- 
nal, em particular aquele político que busca a reeleição, explica não só o sucesso na carreira do candidato tomado individualmente, mas também permite entender o desempenho positivo do seu partido político.

\section{Políticos profissionais e receitas de campanha}

Nos anos recentes, a ciência política brasileira vem se dedicando cada vez mais a medir a influência que os indicadores de financiamento de campanha exercem sobre os resultados das urnas. Os trabalhos feitos nessa área podem ser divididos em dois grandes grupos. O primeiro preocupa-se em identificar a origem dos recursos de financiamento de campanha, isto é, quem são os doadores e para quem direcionam as suas doações. Pode-se dizer que esses trabalhos estão preocupados com a fonte dos recursos e não com seus efeitos nas campanhas (Campos, 2009; Santos, 2011; Speck \& Mancuso, 2012). A outra linha de abordagem do financiamento de campanha preocupa-se mais com os efeitos dos recursos nos resultados das disputas. Esses trabalhos procuram entender a relação existente entre o volume de recursos nas campanhas, as transferências a partidos e o resultado eleitoral (Bourdoukan, 2008; Cervi, 2010; Peixoto, 2009; Rubio, 2005). Pesquisas que analisam tanto eleições majoritárias como proporcionais, em diferentes níveis de disputa (local, regional nacional), têm apontado afinidade entre volume de recursos nas campanhas e maior possibilidade de obtenção de votos. Embora seja necessário considerar outras variáveis (a legislação partidária, o peso das coligações e os perfis dos próprios candidatos), fica evidente uma associação positiva entre dinheiro e voto nas campanhas eleitorais brasileiras.

GRÁFICO 2

MÉDIA DE RECEITA POR OCUPAÇÃO NA ELEIÇÃO PARA A CÂMARA dOS DEPUTAdOS (2010)

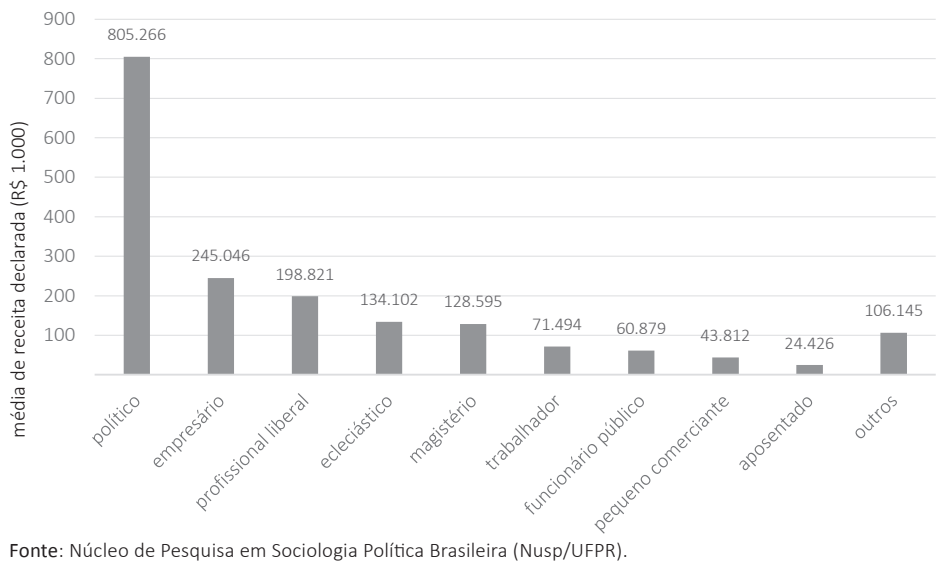

Inspirado na segunda linha de trabalhos, o Gráfico 2 mostra as médias de receitas declaradas dos candidatos a deputado federal (2010), por categoria profissional.

As categorias podem ser divididas em quatro grupos distintos, em função das diferen- 
ças de médias de receitas. Em primeiro lugar encontram-se, novamente, os candidatos que são políticos profissionais. Estes conseguiram uma média de arrecadação de mais de $\mathrm{R} \$ 805$ mil por pretendente, ficando com média quatro vezes superior à segunda categoria, que é a de empresários (média de $\mathrm{R} \$ 245$ mil por campanha individual). Muito próximo dos empresários estão os profissionais liberais, com receitas médias de R\$198 mil por competidor. Depois, um pouco distantes, mas ainda acima de $\mathrm{R} \$ 100$ mil de média, encontram-se os eclesiásticos (R\$ 134 mil de média) e profissionais do magistério (média de $\mathrm{R} \$ 128$ mil). No quarto grupo, com médias abaixo de $\mathrm{R} \$ 100$ mil de receita estão as demais categorias: trabalhadores, funcionários públicos, pequenos comerciantes e aposentados.

Até aqui encontramos que os políticos profissionais tendem a ter mais sucesso eleitoral, mas a diferença está concentrada principalmente no grupo dos candidatos à reeleição, e que os políticos tendem a ter mais receitas de campanha do que os candidatos de outras categorias profissionais. No entanto, os dados agregados por categoria profissional não permitem identificar diferenças entre eleitos e não eleitos dentro das categorias. Por essa razão, apresentamos o Gráfico 3, que mostra as médias de receitas em reais dos candidatos por profissão, separando os eleitos dos não eleitos.

A conclusão a que se pode chegar a partir da imagem é que há forte homogeneidade quanto à capacidade dos eleitos de arrecadarem muito mais recursos que os não eleitos, sejam eles profissionais da política ou não. No entanto, a disputa entre os políticos profissionais é tão competitiva que

\section{GRÁFICO 3}

MÉDIA DE RECEITA DE CAMPANHA POR CANDIDATOS ELEITOS E NÃO ELEITOS NA DISPUTA PARA A CÂMARA dOS DEPUTAdOS (2010)

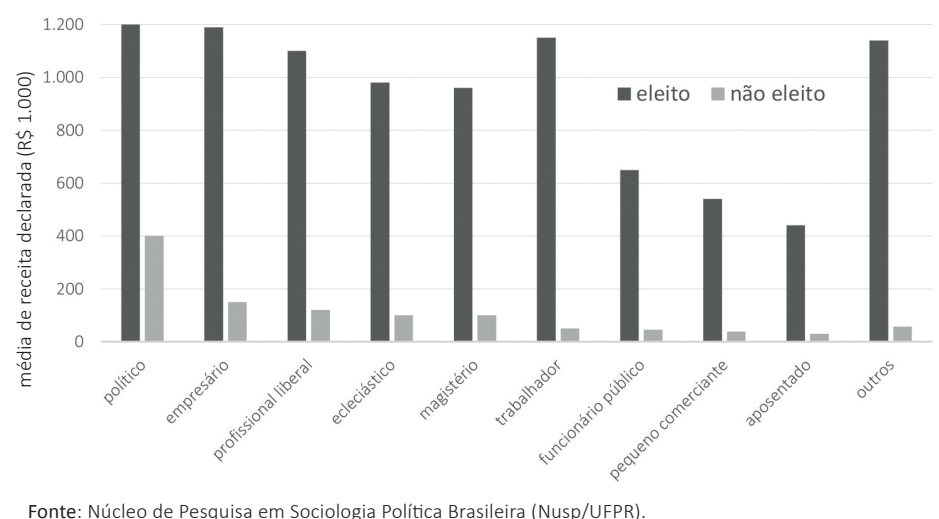

Fonte: Núcleo de Pesquisa em Sociologia Política Brasileira (Nusp/UFPR). somente entre eles a média de arrecadação dos não eleitos se próxima de $\mathrm{R} \$ 400$ mil. Todas as demais categorias ficam abaixo de $\mathrm{R} \$ 200$ mil de média de receitas de campanha por candidato mal sucedido. De forma geral, o dado reforça a proposição que sustenta que os doadores destinam os recursos para políticos profissionais 
5. Como o número de casos varia muito entre as categorias, é preciso tomar cuidado nas comparações diretas entre elas. Além disso, houve apenas um candidato que se declarou prefeito e foi derrotado.

muito mais que para quaisquer outras categorias ocupacionais, de modo que a percepção da existência de uma carreira política por parte os financiadores parece um elemento central na opção do candidato a ser patrocinado (Borges, 2012).

As duas ilustrações que compõem o gráfico 4 representam as médias de receita declarada apenas entre os políticos profissionais candidatos a deputado federal em

\section{GRÁFICO 4}

MÉdIA E DESVIO PADRÃO DE RECEITA DE CAMPANHA DOS "POLÍTICOS" ElEITOS E NÃO ElEitos NA DISPUTA PARA A CÂMARA DOS DEPUTAdOS (2010)

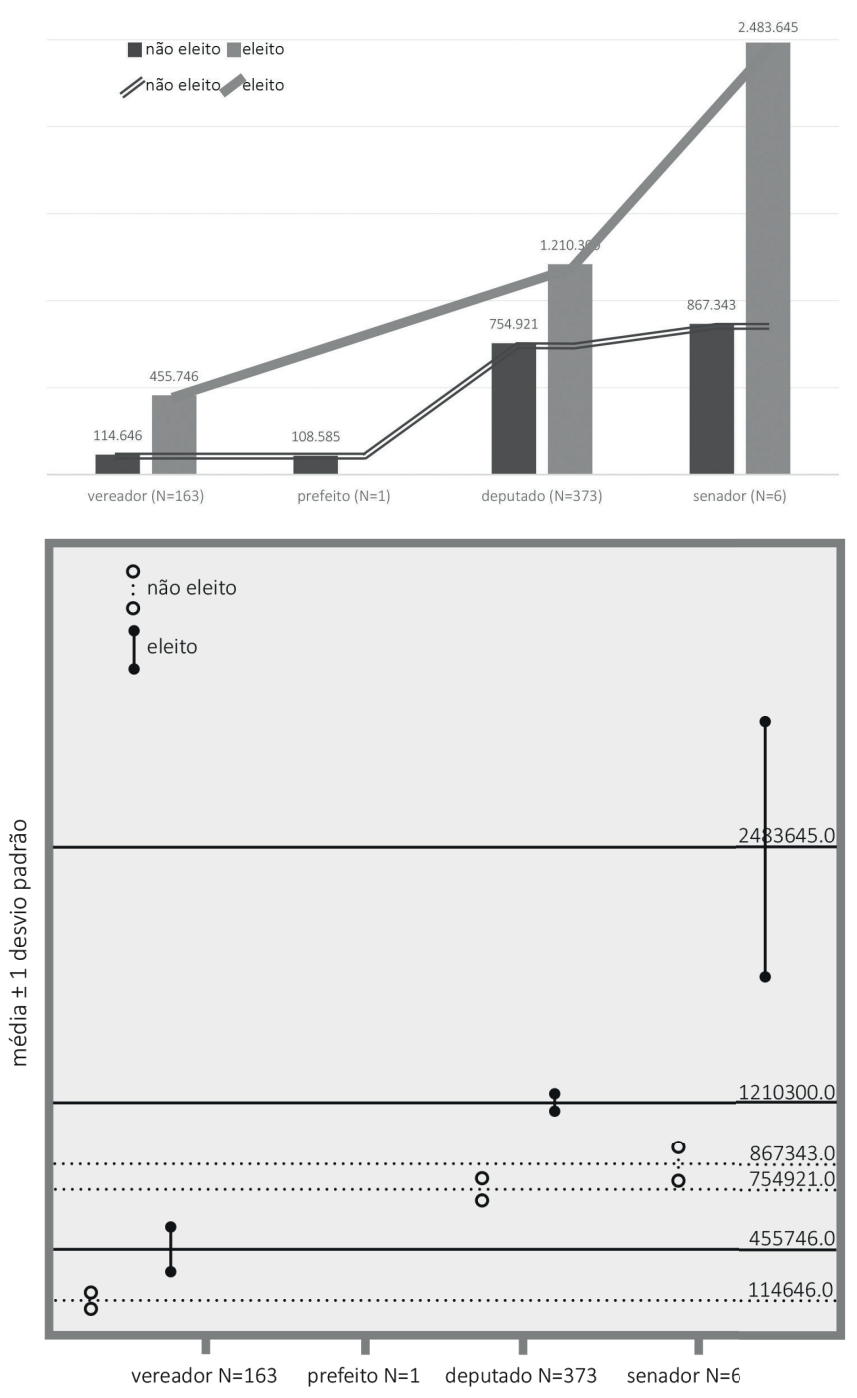

Fonte: Núcleo de Pesquisa em Sociologia Política Brasileira (Nusp/UFPR).
2010, separando-os, mais uma vez, entre eleitos e não eleitos ${ }^{5}$.

Na primeira ilustração do Gráfico 4, é possível perceber que as médias de receitas dos eleitos são sempre maiores que as dos derrotados, independentemente do tipo de político. Entre os não eleitos, vereadores e prefeitos tiveram arrecadações em torno de R\$ 100 mil. Já deputados derrotados arrecadaram em média $\mathrm{R} \$ 750$ mil e os senadores que não conseguiram se eleger apresentaram média de R\$ 960 mil. Por outro lado, entre os eleitos as médias sempre são maiores. Os vereadores apresentaram receita média de R\$ 450 mil, deputados 
reeleitos declararam $\mathrm{R} \$ 1,2$ milhão de arrecadação e os senadores eleitos deputados federais tiveram receita de $\mathrm{R} \$ 2,4$ milhões em média.

Outra informação importante na primeira imagem é o número de níveis entre os cargos políticos. No caso dos derrotados, a linha de tendência mostra apenas dois níveis. Políticos de abrangência municipal (vereador e prefeito) têm arrecadação em torno de $\mathrm{R} \$ 100$ mil e políticos de abrangência regional (deputado e senador) arrecadaram entre $\mathrm{R} \$ 700$ mil e R\$ 800 mil em média. Já entre os eleitos há três níveis bem distintos. Vereador ( $R \$ 450$ mil), deputado ( $R \$ 1,2$ milhão) e senador ( $R \$ 2,4$ milhão) para as campanhas bem sucedidas.

Apesar de bastante ilustrativo, a análise apenas das médias de receitas declaradas não é suficiente, pois ela esconde as variações "internas", ou seja, as diferenças de arrecadação dos candidatos em cada grupo. Para verificar a variabilidade das arrecadações dos tipos de político nos dois grupos, eleitos e não eleitos, foi plotado o gráfico de barra de erro (segunda parte do Gráfico 4$)^{6}$.

As linhas horizontais pontilhadas indicam as médias de cada grupo. Pelo gráfico, é possível perceber que os candidatos vencidos, independentemente do tipo de político, apresentam menores variações (barras mais curtas), indicando serem mais homogêneos no que diz respeito à arrecadação. As barras de erro dos eleitos mostram que a menor variação foi a dos deputados reeleitos. Em segundo lugar vieram os vereadores, com diferença um pouco maior. Por fim, os senadores eleitos deputado federal apresentaram as maiores mudanças em relação à média. Como foram apenas três senadores eleitos, cada ponto da barra apresenta a posição de um deles. Já entre os três senadores derrotados percebe-se uma arrecadação muito próxima da obtida pelos deputados derrotados e abaixo da receita dos deputados reeleitos. Com o que verificamos anteriormente, é possível dizer que ser político profissional fez diferença para se eleger deputado federal em 2010. Todavia, os políticos que já eram deputados tenderam a conseguir mais votos. Além disso, ter receitas altas de campanha também ajuda a explicar o desempenho dos políticos profissionais. Políticos de abrangência municipal tendem a ter menos recursos e maior dificuldade para chegar à Câmara dos Deputados. Políticos de abrangência regional que não conseguem doações significativas tendem a não se eleger.

\section{Considerações finais}

Os elementos apresentados neste artigo permitem sustentar três afirmações referentes às chances de sucesso eleitoral de candidatos às eleições para a Câmara dos Deputados do Brasil, a partir da análise da disputa de 2010.

\footnotetext{
6. As variações foram medidas em apenas um desvio padrão para cima e para baixo da média, pois estamos representando todos os candidatos eleitos e não eleitos, não sendo, portanto, uma amostra.
} 
Quando consideramos o desempenho eleitoral dos concorrentes por ocupação, nenhuma categoria profissional aproxima-se da força eleitoral dos políticos de carreira. Isso confirma os achados substantivos de Braga, Veiga e Miríade 2009; Perissinotto e Miríade 2009; e Perissinotto e Bolognesi 2009. Entretanto, como a oferta de políticos-candidatos envolve um rol de egressos de muitos cargos e todos muito diferentes entre si, é necessário especificar os diversos subtipos de políticos na disputa. Assim, Perissinotto e Bolognesi (2010) demonstraram que, entre os políticos de carreira, o êxito maior se observava para os "políticos do legislativo". Agora pudemos avançar mais um passo ao desagregar essa categoria para constatar que, nesse grupo, os parlamentares oriundos da própria Câmara dos Deputados obtêm melhores resultados vis-à-vis seus competidores das assembleias ou das câmaras municipais. No caso específico da eleição de 2010, o número de deputados federais reeleitos é tão grande que impede qualquer afirmação mais generalizante a respeito do desempenho das demais subcategorias de políticos profissionais naquela disputa.

Além disso, progredimos o conhecimento sobre o tema ao estabelecer que os políticos profissionais estão concentrados nos principais partidos nacionais, aqueles cujas bancadas superam os 40 parlamentares ou mais. E são esses mesmos políticos de carreira que arrecadam mais recursos financeiros e concentram a maior quantidade de dinheiro em suas campanhas (Borges, 2012).

Mas como essas evidências estão relacionadas entre si e, principalmente, o que significam? Em primeiro lugar mostramos que são os políticos profissionais, tal como é possível depreender a ocupação dos dados de registro de candidaturas dos TREs, os que têm as maiores chances de sucesso na disputa analisada. Mais do que isso: conseguimos mostrar que há uma clara hierarquia entre aqueles que se declararam políticos profissionais. Os que eram candidatos à reeleição - isto é, os que já ocupavam cargo de deputado federal - foram aqueles com maiores chances, seguidos pelos senadores e, por fim, pelos vereadores. Esses achados sugerem que 1. para além da capacidade do candidato carrear recursos para sua base eleitoral e 2. para além do tipo de cargo que o político exerce no interior do Legislativo (se ocupante de cargos de comando em comissões ou se membro do "baixo clero" da casa), como sustentam Pereira e Rennó (2001), é importante insistir no fato de que a fonte de sucesso do reeleito é sua condição de profissional da política. Nesse sentido, o acesso à Câmara dos Deputados é muito mais difícil para aqueles que se encontram fora da casa e que desejam progredir por saltos na carreira, como é o caso dos vereadores.

Em segundo lugar, os números indicaram que há forte correlação entre sucesso eleitoral e já ser deputado federal por uma das grandes agremiações partidárias nacionais. Ainda que aqueles que se declararam deputados federais dominem a 
disputa em todos os partidos, há mais deles nas grandes legendas e, nessas, as suas oportunidades de vitória parecem ser ainda maiores. Nesse ponto é interessante notar uma retroalimentação entre o bom desempenho do partido e a presença de políticos de ofício na lista eleitoral. Possivelmente, trata-se de uma via de mão dupla: os grandes partidos selecionam seus candidatos entre políticos já consagrados previamente pelas urnas, ao passo que esses últimos tendem a priorizar organizações com maiores chances de eleição.

Por fim, a pesquisa mostrou que há um claro direcionamento do dinheiro de campanha para aqueles candidatos que já são políticos e que quanto maior a quantidade de recurso, maior a chance de sucesso eleitoral. Sendo político profissional, maior ainda a chance de receber mais recursos. Em eleições em que cada vez mais o financiamento é central, é importante incorporar o perfil social do candidato nas explicações para se dimensionar adequadamente como e especialmente para quem os financiadores canalizam os seus recursos.

Desse modo, há uma espécie de círculo de reforço mútuo no que diz respeito à institucionalização do campo político brasileiro. Aqueles que se profissionalizam são os que têm maiores chances de êxito nas disputas por posições políticas; esses profissionais da política tendem a se concentrar em alguns partidos grandes; os recursos para concorrer ao posto de deputado federal não são distribuídos aleatoriamente, mas tendem a reforçar o processo de profissionalização em questão.

Abstract: Using database containing information on 4,124 candidates for the House of Representatives in the 2010 elections in Brazil, this study evaluates the impact of the variables "occupation", "type of political party" and "campaign financing" on electoral performance. The article concludes that belonging to large and organized political parties, having previous political experience (especially in the House of Representatives itself) and possessing high capacity of collecting financial resources are essential conditions of electoral success in Brazil. These data highlight the professionalism of politicians and the increasing institutionalization of the Brazilian political universe.

Keywords: 2010 elections, deputy, campaign financing, political recruitment, professional politician.

\section{Referências}

BOLOGNESI, B. A seleção de candidaturas no DEM, PMDB, PSDB e PT nas eleições legislativas federais brasileiras de 2010: percepções dos candidatos sobre a formação das listas. Revista de Sociologia e Política, v. 21, n. 46, p. 45-68, Jun. 2013.

BORGES, T. D. P. Os partidos políticos e o financiamento empresarial das campanhas legislativas para a Câmara dos Deputados: um estudo sobre as doações empresariais e as carreiras nas eleições de 2006. Paper apresentado no XXXVI Encontro Anual da Anpocs. Anais... Águas de Lindoia (SP), Out. 2012. 
BOURDIEU, P. A representação política. Elementos para uma teoria do campo político. In: BOURDIEU, P. O poder simbólico. 2. ed. Rio de Janeiro: Bertrand Brasil, 1998.

- Conférence: le champ politique. In: BOURDIEU, P. Propos sur le champ politique, p. 49-80. Lyon: Presses Universitaires de Lyon, 2000.

BOURDOUKAN, A. Y. Financiamento político em perspectiva comparada. Paper apresentado no VI encontro da Associação Brasileira de Ciência Política (ABCP). Anais... Campinas, Jul. 2008.

BRAGA, M. do S. S.; VEIGA, L. F.; MIRÍADE, A. Recrutamento e perfil dos candidatos e dos eleitos à Câmara dos Deputados nas eleições de 2006. Revista Brasileira de Ciências Sociais, v. 24, n. 70, p. 123-142, Jun. 2009.

CAMPOS, M. M. Democracia, partidos e eleições: os custos do sistema partidário-eleitoral no Brasil. Belo Horizonte: Universidade Federal de Minas Gerais, 2009.

CERVI, E. U. Financiamento de campanhas e desempenho eleitoral no Brasil: análise das contribuições de pessoas físicas, jurídicas e partidos políticos às eleições de 2008. Revista Brasileira de Ciência Política, n. 4, p. 135-167, 2010.

GALLAGHER, M.; MARSH, M. (Eds.). Candidate selection in comparative perspective: the secret garden of politics. London; Newbury Park; Beverly Hills: Sage Publications, 1988.

GAXIE, D. Les logiques du recrutement politique. Revue Française de Science Politique, v. 30, n. 1, p. 5-45, 1980.

MARENCO DOS SANTOS, A. Não se fazem mais oligarquias como antigamente: recrutamento parlamentar, experiência política e vínculos partidários entre deputados brasileiros (1946-1998). Porto Alegre: Universidade Federal do Rio Grande do Sul, 2000.

MARENCO DOS SANTOS, A.; SERNA, M. Por que carreiras políticas na esquerda e na direita não são iguais? Recrutamento legislativo em Brasil, Chile e Uruguai. Revista Brasileira de Ciências Sociais, v. 22, n. 64, p. 93-113, Jun. 2007.

NORRIS, P. Introduction: theories of recruitment. In: NORRIS, P. (Ed.). Passages to power. Legislative recruitment in advanced democracies. Cambridge: Cambridge University Press, 1997.

PEIXOTO, V. DE M. Modelos de financiamento de campanhas e accountability: uma análise comparativa e um teste de hipótese. Perspectivas: Revista de Ciências Sociais, n. 35, p. 91-116, 2009.

PEREIRA, C.; RENNÓ, L. O que é que o reeleito tem? Dinâmicas político-institucionais locais e nacionais nas eleições de 1998 para a Câmara dos Deputados. Dados, v. 44, n. 2, p. 133-172, 2001. 
PERISSINOTTO, R. M.; BOLOGNESI, B. Electoral success and political institutionalization in the federal deputy elections in Brazil (1998, 2002 and 2006). Brazilian Political Science Review, v. 4, n. 1, p. 10-32, 2010.

PERISSINOTTO, R. M.; MIRÍADE, A. Caminhos para o parlamento: candidatos e eleitos nas eleições para deputado federal em 2006. Dados, v. 52, n. 2, p. 301-333, 2009.

PUTNAM, R. D. The comparative study of political elites. Englewood Cliffs, N.J.: Prentice Hall, 1976.

RAHAT, G.; HAZAN, R. Y. Candidate selection methods: an analytical framework. Party Politics, v. 7, n. 3, p. 297-322, Maio 2001.

RODRIGUES, L. M. Partidos, ideologia e composição social: um estudo das bancadas partidárias na Câmara dos Deputados. São Paulo: Edusp, 2002.

Mudanças na classe política brasileira. São Paulo: PubliFolha, 2006.

RUBIO, D. F. Financiamento de partidos e campanhas: fundos públicos versus fundos privados. Novos Estudos Cebrap, n. 73, p. 6-16, Nov. 2005.

SANTOS, R. D. Grandes empresários e sucesso eleitoral nas eleições de 2002, 2006 e 2010. Paper apresentado no XXXV Encontro Anual da Anpocs. Anais... Caxambu, Out. 2011.

STANWORTH, P.; GIDDENS, A. Elites and power in British Society. Cambridge: Cambridge University Press, 1974.

SPECK, B.; MANCUSO, W. P. Financiamento, capital político e gênero: um estudo de determinantes do desempenho eleitoral nas eleições legislativas brasileiras de 2010. Paper apresentado no XXXVI Encontro Anual da Anpocs. Anais... Águas de Lindoia, 2012. 